\title{
Homogeneous and robust PolyProline type I helices from peptoids with non-aromatic $\alpha$-chiral side chains
}

\author{
Olivier Roy, ${ }^{*} \dagger$ Geoffrey Dumonteil, ${ }^{\dagger}$ Sophie Faure, ${ }^{\dagger}$ Laurent Jouffret, ${ }^{\dagger}$ Alexandre Kriznik, ${ }^{\ddagger}$ and \\ Claude Taillefumier*,† \\ †Université Clermont Auvergne, Université Blaise Pascal, Institut de Chimie de Clermont-Ferrand, BP 10448, F- \\ 63000 Clermont-Ferrand, France and CNRS, UMR 6296, ICCF, F-63178 Aubière Cedex, France \\ ‡Université de Lorraine, Fédération de Recherche CNRS 3209, Service Commun de Biophysique Interactions Molé- \\ culaires, and Laboratoire Ingénierie Moléculaire et Physiopathologie Articulaire, CNRS, UMR 7365, BP 20199, F- \\ 54505 Vandoeuvre les Nancy, France
}

\begin{abstract}
Peptoids which are oligomers of $N$-substituted glycines represent a class of peptide mimics with great potential in areas ranging from medicinal chemistry to biomaterial science. Controlling the equilibria between the cis and trans conformations of their backbone amides is the major hurdle to overcome for the construction of discrete folded structures, particularly for the development of all-cis PolyProline-type I (PPI) helices, as tools for modulating biological functions. The prominent role of backbone to side chain electronic interactions $\left(n \rightarrow \pi^{*}\right)$ and side chains bulkiness in promoting cis-amides was essentially investigated with peptoid aromatic side chains among which the chiral 1-naphthylethyl (Inpe) group yielded the best results. We have explored for the first time the possibility to achieve similar performances with a sterically hindered $\alpha$-chiral aliphatic side chain. Herein, we report on the synthesis and detailed conformational analysis of a series of $(S)-N$-(1-tert-butylethyl)glycine (Ns1tbe) peptoid homooligomers. The X-ray crystal structure of an Ns1tbe pentamer revealed an all-cis PPI helix and the CD curves of the Ns1tbe oligomers also resemble those of PPI peptide helices. Interestingly, the CD data reported here are the first for any conformationally homogeneous helical peptoids containing only $\alpha$-chiral aliphatic side chains. Finally we also synthesized and analysed two mixed oligomers composed of $N t \mathrm{Bu}$ and $N s 1$ tbe monomers. Strikingly, the solid state structure of the mixed oligomer $\mathrm{Ac}-(t \mathrm{Bu})_{2}-$ (s1tbe $)_{4}-(t \mathrm{Bu})_{2}-\mathrm{COO} t \mathrm{Bu}$, the longest to be solved for any linear peptoid revealed a PPI helix of great regularity despite the presence of only $50 \%$ of chiral side chain in the sequence.
\end{abstract}

\section{INTRODUCTION}

Peptoids are artificial oligomers/polymers composed of $N$-Substituted Glycine (NSG) monomers that are becoming a valuable class of compounds in biosciences ${ }^{1}$ as well as in important chemical areas including catalysis, ${ }^{2}$ selfassembly ${ }^{3}$ and metal binding. ${ }^{4}$ Compared to natural peptides, the side chains are shifted from the $\mathrm{C} \alpha$ carbons to the amide bond nitrogen atoms. This change has important implications on the conformational behaviour of this class of compounds whose main chain is more flexible than that of their parent peptides. This difference is essentially due to the presence of $N, N$-disubstituted amide bonds, often referred as tertiary amides, with no hydrogen bond donor atoms for establishing intramolecular $\mathrm{H}$-bonding interactions, and also to the fact that in most cases the cis and trans conformations of the amide bonds are very close in energy giving rise to cis/trans equilibria. ${ }^{5}$ Despite their inherent flexibility, peptoids have been shown to adopt preferential folded conformations, including the PolyProline-type II (PPII) ${ }^{6}$ and PolyProline-type I (PPI) helical structures. ${ }^{7}$ The potential of foldamer helices from a drug discovery standpoint has been recognized but for some of them a limitation exists in term of diversity of accessible monomers. ${ }^{8}$ In the case of peptoids a huge diversity of side chains can be incorporated but only few of them are capable of promoting a stable secondary structure. The canonical PPI helix with all-cis amide bonds was the first to be predicted by molecular mechanics calculations from prototypical oligopeptoids composed of chiral $(S)-\mathrm{N}$-(1-phenylethyl)glycine residues (spe). ${ }^{7}$ Soon after, the PPI-type conformation was con- 
firmed by NMR of the (Nspe) ${ }_{5}$ homopentamer, the all-cis structure being the major solution conformation among a mixture of cis/trans isomers. ${ }^{9}$ In a recent past, intensive efforts have been made for a clear understanding of the local stereoelectronic factors that govern the cis/trans peptoid amides equilibria. This research led to the development of side chains capable of exercising a strong steric and/or electronic control over the amide geometry and consequently on the conformation in the vicinity of the studied amide. Thus, a number of side chains were examined with respect to their ability to promote the cis conformation. Those that yielded the best performances to date are presented in Figure $1 B .{ }^{10,11,12,13}$ It must be pointed out here that most of them have an aromatic group in their structure which is a limitation in term of physicochemical properties in a drug discovery context as for example the disruption of protein-protein interactions. In this work we have sought to identify a non-aromatic cispeptoid amide inducer allowing the formation of discrete PPI helices of defined handedness. This challenge was never achieved from peptoid oligomers with $\alpha$-chiral aliphatic side chains. Thus our goal was also to describe more precisely the $C D$ signature of non-aromatic PPI peptoid. In view of our understanding of the noncovalent interactions that govern local peptoid folding, the first objective was to identify a chiral aliphatic side chain bringing the maximum of steric hindrance. As a precursor of this ideal side chain, it was also important for this work to identify a commercially primary amine available in the $R$ and $S$ configurations. We report here the synthesis of a series of (S)-N-(1-tert-butylethyl)glycine (Nsitbe) homooligomers and two mixed oligomers composed of Nsitbe and $N t \mathrm{Bu}$ monomers, and their detailed structural analysis by NMR spectroscopy, X-ray crystallography and CD analysis.

\section{RESULTS AND DISCUSSIONS}

\subsection{Synthesis of peptoid oligomers}

The commercially available (2S)-3,3-dimethylbutan-2amine was used as the precursor of the sitbe side chain. Its enantiomeric $R$ form is also commercially available. Peptoids are most often synthesized by the so-called solid-phase submonomer synthesis ${ }^{14}$ but this method can results in low yields in case of very bulky amines like the 1-naphthylethyl amine or the tert-butyl amine for which

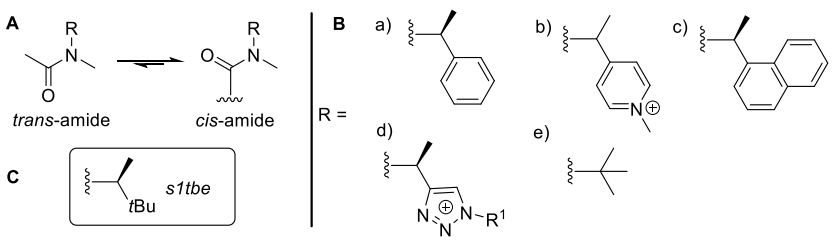

Figure 1. (A) Cis-trans peptoid amide equilibrium. (B) Chemical structure of side chains promoting the cis conformation: a) (S)-1-phenylethyl (spe); b) 4-methylpyridinium (4mpy);10 c) (S)-1-naphthylethyl (sinpe); ;0,11 d) with $\mathrm{R}^{1}=\mathrm{Bn}, \mathrm{1}^{-}$ (benzyltriazolium)ethyl $\left(b_{t e}\right)^{+}{ }^{12}$ e) tert-butyl $(t \mathrm{Bu}) .^{13}$ all attempts of solid-phase synthesis yielded mixtures of truncated $(\mathrm{N} t \mathrm{Bu})$ oligomers. ${ }^{15}$ The solution-phase submonomer synthesis was therefore preferred for this study. In order to compare the efficacy of the new sitbe side chain to the past work with the sinpe side chain, ${ }^{\text {,1a }}$ which can be considered today as the reference for constructing robust peptoid helical structures, we chose to synthesize a series of acetamide-capped (Nitbe) homooligomers with $t \mathrm{Bu}$ esters at their C-termini. This series comprises all the oligomers from the monomer till the hexamer (1-6), the octamer (8) and the nonamer (9) (Table 1). The synthesis started by substitution of the bromine atom of tertbutyl bromoacetate by the sitbe amine, yielding a Nitbe monomer which was then elongated by the iterative submonomer method consisting in a two-step acylationsubstitution cycle. Bromoacetic anhydride, freshly prepared from bromoacetic acid and DCC, was systematically used for the acylation steps and the substitutions were carried out with 3 equivalents of the sitbe amine. ${ }^{13}$ After each iteration, with the exception of the heptamer stage, a portion of the formed amine was acetylated to yield peptoids 1-6, 8 and 9. The same procedure was applied for synthesizing the mixed oligomers 6'and 8' (Table 1) by using when required $t \mathrm{BuNH}_{2}$ instead of the sitbe amine (see Scheme Si for details). The Nsch hexamer 7 composed of (S)-N-(1-cyclohexylethyl)glycine units with an acetylated $\mathrm{N}$-terminus and a tert-butyl ester at the Cterminus, was also synthesised as a key control to allow for spectroscopic comparison. ${ }^{16}$

\section{Table 1. Structures for peptoids 1-9, 6' and 8'}

\begin{tabular}{|c|c|}
\hline peptoid & Monomer sequence \\
\hline 1 & Ac-sitbe-COOtBu \\
\hline 2 & $\mathrm{Ac}-(\mathrm{sitbe})_{2}-\mathrm{COO} t \mathrm{Bu}$ \\
\hline 3 & $\mathrm{Ac}-(\text { sitbe })_{3}-\mathrm{COO} t \mathrm{Bu}$ \\
\hline 4 & $\mathrm{Ac}-\left(\right.$ sitbe $_{4}-\mathrm{COO} t \mathrm{Bu}$ \\
\hline 5 & $\mathrm{Ac}-\left(\text { sitbe }_{5}\right)_{5} \mathrm{COO} t \mathrm{Bu}$ \\
\hline 6 & $\mathrm{Ac}-\left(\right.$ sitbe $_{6}-\mathrm{COO} t \mathrm{Bu}$ \\
\hline 7 & Ac- $(s c h)_{6}-\mathrm{COO} t \mathrm{Bu}$ \\
\hline 6 & $\mathrm{Ac}-t \mathrm{Bu}(\text { sitbe })_{4} t \mathrm{Bu}-\mathrm{COO} t \mathrm{Bu}$ \\
\hline 8 & Ac- $(\text { sitbe })_{8}-\mathrm{COO} t \mathrm{Bu}$ \\
\hline 8 & $\mathrm{Ac}-(t \mathrm{Bu})_{2}(\text { sitbe })_{4}(t \mathrm{Bu})_{2}-\mathrm{COO} t \mathrm{Bu}$ \\
\hline 9 & $\mathrm{Ac}-\left(\right.$ sitbe $_{9}-\mathrm{COO} t \mathrm{Bu}$ \\
\hline
\end{tabular}

\subsection{NMR analysis of peptoid oligomers}

${ }^{1} \mathrm{H}$ NMR of monomer 1 was recorded at a concentration of $10 \mathrm{mM}$ in various solvents $\left(\mathrm{CDCl}_{3}, \mathrm{CD}_{3} \mathrm{CN}\right.$ and $\left.\mathrm{CD}_{3} \mathrm{OD}\right)$ for determining the $K_{\text {cis/trans }}$ ratios (Table 2). They were calculated by averaging the integration of three sets of related rotamer signals, including when possible the $\mathrm{NC} \alpha$ methyne protons. The chemical shift of the methyne proton in monomer $\mathbf{1}$ is remarkably deshielded in the cis conformation relative to the trans $\left(\sim 1 \mathrm{ppm}\right.$ in $\left.\mathrm{CDCl}_{3}\right)$, 
Table 2. Overall $K_{\text {cis/trans }}$ values as determined by ${ }^{1} \mathbf{H}$ $\mathrm{NMR}$ integration and/or ${ }^{1} \mathrm{H}-\mathrm{COSY}$ in $\mathrm{CDCl}_{3}, \mathrm{CD}_{3} \mathrm{CN}$ and $\mathrm{CD}_{3} \mathrm{OD}$

\begin{tabular}{cccc}
\hline \multirow{2}{*}{ peptoid } & $\mathrm{CDCl}_{3}$ & $\mathrm{CD}_{3} \mathrm{CN}$ & $\mathrm{CD}_{3} \mathrm{OD}$ \\
\cline { 2 - 4 } & $K_{\text {cis/trans }}$ & $K_{\text {cis/trans }}$ & $K_{\text {cis/trans }}$ \\
\hline 1 & $0.64^{\mathrm{a}}$ & $0.67^{\mathrm{a}}$ & $0.77^{\mathrm{a}}$ \\
2 & $0.98^{\mathrm{a}}$ & $1.60^{\mathrm{a}}$ & $1.68^{\mathrm{a}}$ \\
3 & $1.95^{\mathrm{a}}$ & $2.61^{\mathrm{a}}$ & $3.00^{\mathrm{a}}$ \\
4 & $>19^{\mathrm{b}}$ & $10.89^{\mathrm{a}}$ & $>19^{\mathrm{b}}$ \\
5 & $18.92^{\mathrm{a}}$ & $7.96^{\mathrm{a}}$ & $>19^{\mathrm{b}}$ \\
6 & $>19^{\mathrm{a}}$ & $10.39^{\mathrm{a}}$ & $>19^{\mathrm{b}}$ \\
7 & $2.71^{\mathrm{c}}$ & $1.39^{\mathrm{c}}$ & \\
6 & $>19^{\mathrm{b}}$ & $>19^{\mathrm{b}}$ & \\
8 & $>19^{\mathrm{a}}$ & $8.08^{\mathrm{a}}$ & $>19^{\mathrm{b}}$ \\
8 & $>19^{\mathrm{b}}$ & $>19^{\mathrm{b}}$ & \\
9 & $>19^{\mathrm{a}}$ & $12.13^{\mathrm{a}}$ & $>19^{\mathrm{b}}$ \\
\hline
\end{tabular}

${ }^{\mathrm{a}}$ Determined by integration of $1 \mathrm{D}-{ }^{1} \mathrm{H}$ NMR spectrum. ${ }^{\mathrm{b}}$ Determined by integration of $2 \mathrm{D}-{ }^{-1} \mathrm{H}-\mathrm{COSY}$ spectrum. ${ }^{\mathrm{c}}$ Determined by integration of 2D-HSQC spectrum.

in accordance with previously ${ }^{1} \mathrm{H}$ NMR reported data on aliphatic and aromatic side chains. ${ }^{10,11 a, 12,17}$ The methyne protons resonances are thus a good way for discriminating the cis and trans rotamers of the Nsitbe family. Monomer 1 which exhibits $K_{\text {cis/trans }}$ ranging between 0.64 and 0.77 displays only slight sensitivity with solvent polarity, in line with previous observations of ester-capped monomer models, relative to related amide-capped systems. ${ }^{10}$ These values are similar to those observed for the pe side chain in the methyl ester model A (Figure 2) for which an $n \rightarrow \pi_{\text {Ar }}^{*}$ interaction stabilizing the cis rotamer has been suggested..$^{10}$ Interestingly, the $K_{\text {cis/trans }}$ for compound 1 are 2-fold higher than those for the model $\mathbf{C}$ containing the
A<smiles>COC(=O)CN(C(C)=O)C(C)c1ccccc1</smiles>

$\mathrm{CDCl}_{3}(0.66)$ $\mathrm{CD}_{3} \mathrm{CN}(0.67)$ $\mathrm{CD}_{3} \mathrm{OD}(0.75)$

E<smiles>CC(=O)N(CC(=O)N1CCCCC1)C(C)(C)C</smiles>

$\mathrm{CD}_{3} \mathrm{CN}(>19)$
B

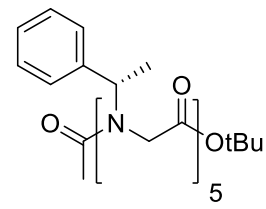

$\mathrm{CD}_{3} \mathrm{CN}(3.3)$
$\mathbf{F}$

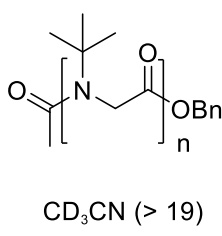

C<smiles>COC(=O)CN(C(C)=O)C(C)C1CCCCC1</smiles>

$\mathrm{CDCl}_{3}(0.31)$

$\mathrm{CD}_{3} \mathrm{CN}(0.29)$

$\mathrm{CD}_{3} \mathrm{OD}(0.38)$

G

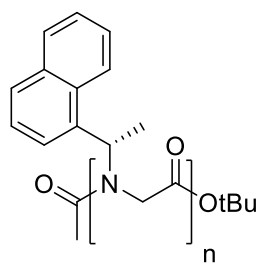

$\mathrm{n}$
$\mathrm{CD}_{3} \mathrm{CN} \begin{aligned} & \mathrm{n}=1(4.9), \mathrm{n}=2(10.8) \\ & \mathrm{n}=3(16), \mathrm{n}>4(>19)\end{aligned}$ aliphatic cyclohexyl (ch) side chain, which served as a with the $t B u$ side chain which suppressed comresults from complementary steric and $n \rightarrow \pi_{\text {Ar }}^{*}$ effects. A larger overall $K_{c}$. 1.6o) relative to the value observed in chloroform o.98). One possible explanation is that backbone $K_{\text {cis/trans }}$ evolve with the oligomer length, is the great leap between the trimer and tetramer stage, particuin chloroform and methanol. Taking the example of induced a dramatic increase of conformational ordering. This phenomenon is much more pronounced with the sitbe system as compared with the Nsinpe for which the $K_{\text {cis/trans }}$ is more regular going from the they possess identical $N$ - and $C$-capping groups and have been studied both in acetonitrile. A $K_{\text {cis/trans }}$ of 3.3 for Ac(Nspe) ${ }_{5}-\mathrm{CO}_{2} t \mathrm{Bu}$ in $\mathrm{CD}_{3} \mathrm{CN}$ (B, Figure 2), has also been described as part of the study of the Nisnpe system. ${ }^{11 a}$

$=3(16), n>4(>19)$

Figure 2. $K_{\text {cis/trans }}$ values (the number in brackets) of various model peptoids and oligomers as determined by NMR measurements in different solvents. In the lower right corner, the structure of the homo-oligomers synthesized in this work. 
This value is far lower than that of pentamer $\mathbf{5}$ $\left(\mathrm{CD}_{3} \mathrm{CN} K_{\text {cis/trans }}=7.96\right)$, and it should also be noted that switching from acetonitrile to chloroform or methanol increased $K_{\text {cis/trans }}$ by 2.4 -fold. As already mentioned the cyclohexylethyl side chain represents a baseline to assess the effectiveness of aliphatic side chains. A modest $\mathrm{CD}_{3} \mathrm{CN} K_{\text {cis/trans }}$ value of 1.0 was described for hexamer $\mathrm{H}$ $(\mathrm{Nsch})_{6}-\mathrm{CONH}_{2}$ (D, Figure 2). ${ }^{16} \mathrm{~A}$ very close value was measured in acetonitrile for the synthesized peptoid 7 $\left(\mathrm{CD}_{3} \mathrm{CN}^{\mathrm{C}} K_{\text {cis/trans }}=1.39\right)$ and increased significantly in chloroform $\left({ }^{\mathrm{CDCl}_{3}} K_{\text {cis/trans }}=2.71\right)$ but still far behind the value measured for hexamer $6\left({ }^{\mathrm{CDCl}_{3}} K_{\text {cis/trans }}=>19\right)$. The effec- tiveness of the sitbe is definitely out of proportion with the sch and reached unprecedented levels for an aliphatic side chain. Remarkably, the heterooligomers Ac$(t B u)(\text { sitbe })_{4}(t B u)-\mathrm{CO}_{2} t \mathrm{Bu}\left(6^{\prime}\right)$ and Ac- $(t B u)_{2}(\text { sitbe })_{4}(t B u)_{2-}$ $\mathrm{CO}_{2} t \mathrm{Bu}\left(8^{\prime}\right)$ exhibit overall amide $K_{\text {cis/trans }}$ higher than 19 in $\mathrm{CDCl}_{3}$ and $\mathrm{CD}_{3} \mathrm{CN}$ which means in other words that the trans-amide conformation was undetectable. The overall $K_{\text {cis/trans }}$ measured for 6' and 8' correspond in fact to those of the tetrameric central chiral segment of the oligomers since they were determined from the NMR
A

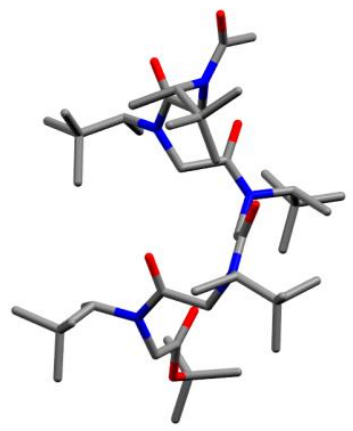

B

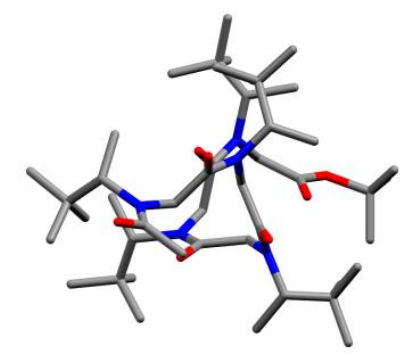

$\mathrm{C}$

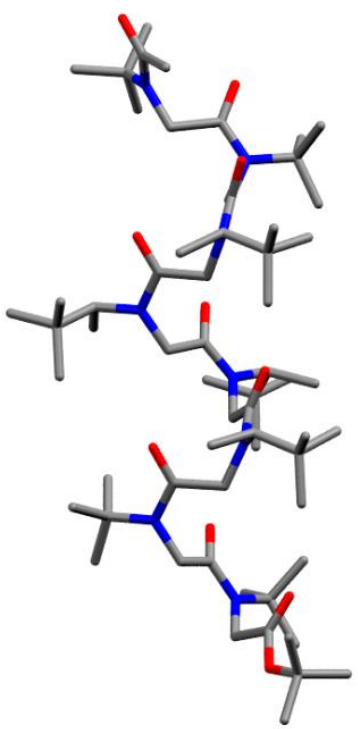

$\mathrm{D}$
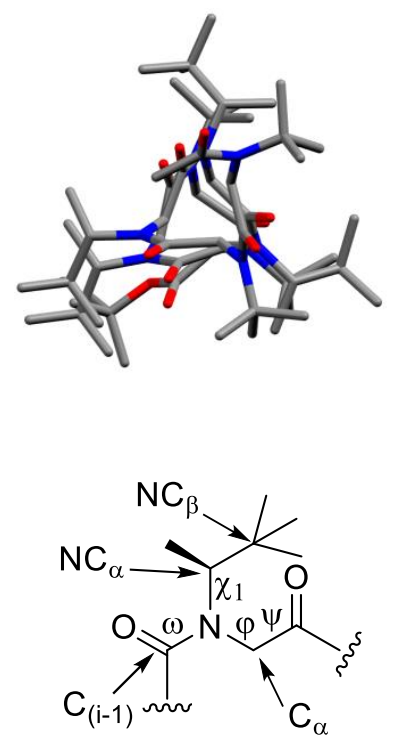

Figure 3. Solid-state structures of compounds $\mathbf{5}$ and $\mathbf{8}$ 'determined by X-ray crystallography (A-D) and dihedral angles definition (lower right corner). Views perpendicular to the helical axis (A: compound $5, \mathrm{C}$ : compound 8'). Views parallel to the helical axis from the N-terminus (B: compound 5, D: compound 8'). Atom colours: grey, carbon; red, oxygen; blue, nitrogen. Hydrogen atoms are omitted for clarity. Dihedral angles definition (upper left corner): $\omega\left[\mathrm{C}_{\alpha}(i-1) ; \mathrm{C}(i-1) ; \mathrm{N} ; \mathrm{C}_{\alpha}\right], \varphi\left[\mathrm{C}(i-1) ; \mathrm{N} ; \mathrm{C}_{\alpha} ; \mathrm{C}\right], \psi\left[\mathrm{N} ; \mathrm{C}_{\alpha}\right.$; $C ; \mathrm{N}(i+1)], \chi_{1}\left[\mathrm{C}(i-1) ; \mathrm{N} ; \mathrm{NC}_{\alpha} ; \mathrm{NC}_{\beta}\right]$

integration of the methyne protons of the sitbe side chains, but past studies from our group have shown that peptoid amides bearing the $t \mathrm{Bu}$ side chain only populate the cis conformation. ${ }^{3}$ The tetrameric central chiral segment in 6' and 8' is thus conformationally homogeneous in solution with all peptoid amides in the cis conformation in $\mathrm{CDCl}_{3}$ and $\mathrm{CD}_{3} \mathrm{CN}$. This is not the case of tetramer 4 which exhibits lower overall $K_{\text {cis/trans }}$ in $\mathrm{CD}_{3} \mathrm{CN}$ (10.89). The $\mathrm{N} t \mathrm{Bu}$ residues at the extremities of $\mathbf{6}^{\prime}$ and $\mathbf{8}^{\prime}$ thus help promote a higher conformational homogeneity of the inner chiral segment of these oligomers relative to tetramer 4 .

\subsection{X-ray studies for peptoids 5 and 8'}

Crystals of peptoid $\mathbf{5}$ were grown via slow evaporation from isopropanol solution and solved in the $P_{2_{1} 2_{1}}$ space group. As expected, compound 5 adopts a right-handed helix with $\sim 3$ residues per turn and a pitch of $\sim 6 \AA$, simi- lar to a PPI helix (Figure $3 \mathrm{~A}, \mathrm{~B}$ ) and in accordance with the $\mathrm{X}$-ray crystal structure of tetramer Ac-(1snpe) 4- $^{-}$ $\mathrm{CO}_{2} t \mathrm{Bu}^{\text {11a }}$ but slightly lower than that determined from the X-ray structure of the aliphatic Nrch pentamer $(\sim 6.7$ $\AA) .{ }^{16}$ The pitch of compound $\mathbf{5}$ in the solid was accurately measured between the methylene carbon atoms of residues 1 and 4 (6.1 $\AA$ ) on the one hand and residues 2 and 5 (5.9 $\AA$ ) on the other (Figure $S_{3}$ ). Similarity of the values is a first indication of conformational regularity of the helical structure. This is reflected by the regularity of the dihedral angles and particularly those of the internal residues 2,3 and 4 that do not differ by more than $1.3^{\circ}$ for $\omega$ and $\varphi, 4.2^{\circ}$ for $\chi 1$, and $3.4^{\circ}$ for $\psi$ (Table 3 ). In contrast with the reference pentamer $\mathrm{H}-(r \mathrm{ch})_{5}-\mathrm{CONH}_{2},{ }^{16}$ the $\omega$ amide dihedral angles of $\mathbf{5}$ significantly deviate from planarity, with values ranging from -15.8 to -9.7 . The most important deviations of $\omega$ peptoid amides have been previously observed for constrained cyclic peptoids ${ }^{18}$ and also 
in the X-ray crystallography of Nisnpe peptoids, ${ }^{\text {11a }}$ commensurate with the bulkiness of the side chain. The $\chi_{1} \approx-$ $103^{\circ}\left(\mathrm{C}_{(i-1)} ; \mathrm{N} ; \mathrm{N}-\mathrm{C} \alpha ; \mathrm{N}-\mathrm{C} \beta\right.$ dihedral angle as depicted in Figure 3) results in a conformation in which the amide carbonyl and the $\mathrm{N}-\mathrm{C} \alpha-\mathrm{H}$ bonds are roughly eclipsed. Stabilization of this conformation is likely to be attributed in part to $\mathrm{C}-\mathrm{H} \cdots \mathrm{O}=\mathrm{C}$ interactions involving the methyne protons of sitbe side chains and the carbonyl peptoid amides as discussed in recent studies. ${ }^{19,11 b}$

Table 3. Observed dihedral angles for Ac-(stbe $)_{5}-\mathrm{COO} t \mathrm{Bu}$ $\mathbf{5}$ as determined by X-ray crystallography

\begin{tabular}{ccccc}
\hline residue & $\omega$ & $\varphi$ & $\psi$ & $\chi \mathbf{1}$ \\
\hline 1 & $-15.8(2)$ & $-73.4(2)$ & $-164.6(2)$ & $-103.2(1)$ \\
2 & $-14.4(2)$ & $-67.3(2)$ & $-176.8(2)$ & $-100.2(2)$ \\
3 & $-14.4(2)$ & $-68.3(2)$ & $-178.8(1)$ & $-104.4(2)$ \\
4 & $-15.7(2)$ & $-67.0(2)$ & $175.4(2)$ & $-103.2(2)$ \\
5 & $-9.7(2)$ & $-81.9(2)$ & - & $-103.9(2)$ \\
\hline
\end{tabular}

Table 4. Observed dihedral angles for Ac$(t B u)_{2}(\text { sitbe })_{4}(t B u)_{2}-\mathrm{COO} t \mathrm{Bu} \mathbf{8}^{\prime}$ as determined by X-ray crystallography

\begin{tabular}{ccccc}
\hline monomer & $\omega$ & $\varphi$ & $\psi$ & $\chi \mathbf{1}$ \\
\hline $\mathbf{1}(\boldsymbol{t B u})$ & $-1.1(5)$ & $-89.2(4)$ & $-175 \cdot 3(3)$ & \\
$\mathbf{2}(\boldsymbol{t B u})$ & $-14.0(4)$ & $-76.6(3)$ & $-170.0(3)$ & \\
$\mathbf{3}($ sitbe $)$ & $-4.7(4)$ & $-71.7(3)$ & $-176.8(3)$ & $-99.9(3)$ \\
$\mathbf{4}($ sitbe $)$ & $-6.3(4)$ & $-69.4(3)$ & $177.4(3)$ & $-98.4(3)$ \\
$\mathbf{5}($ sitbe $)$ & $-6.9(4)$ & $-66.5(4)$ & $171.0(3)$ & $-100.9(3)$ \\
$\mathbf{6}(\mathbf{s i t b e})$ & $-0.9(4)$ & $-68.4(4)$ & $169.2(3)$ & $-105.2(3)$ \\
$\mathbf{7}(\boldsymbol{t B u})$ & $7.1(4)$ & $-84.6(3)$ & $-178.9(3)$ & \\
$\mathbf{8}(\boldsymbol{t B u})$ & $-2.0(4)$ & $-85.4(3)$ & $-172.4(4)$ & \\
\hline
\end{tabular}

However the $\chi 1$ dihedral angles of 5 are about $20^{\circ}$ smaller than the predicted values in gas phase for Nspe oligomers. ${ }^{7}$ They are also significantly smaller $\left(\sim 10-25^{\circ}\right)$ than those measured in the crystals of the Nrch and Nisnpe systems. Determination of the interactions responsible for this discrepancy is not obvious. This might be a consequence of attractive dispersion interactions between hydrocarbon moieties, ${ }^{20}$ notably short intra-residue $\mathrm{H} \cdot \cdots \mathrm{H}$ contacts between the backbone $\mathrm{CH}_{2}$ and the $\mathrm{NC} \alpha$ methyl hydrocarbons of sitbe side chains which are in the range 2.1-2.3 $\AA$ (see Supporting Information, S33).

The conformation of the mixed octamer 8' was also investigated by X-ray diffraction. Single crystals, suitable for Xray crystallography were grown via slow evaporation from isopropanol solution of $\mathbf{8}^{\prime}$. They were solved in the $P_{\mathbf{2}_{1} \mathbf{2}_{1}}$ space group. The X-ray structure of $\mathbf{8}$ revealed the typical PPI-type helical conformation of peptoids with cis-amide bonds and approximately three residues per turn, but what is absolutely remarkable, is that this structure is the longest to be solved for any linear peptoid to date. While the previous solved tetramer and pentamers revealed essentially one helical turn showing a nascent helix, the structure of $\mathbf{8}^{\prime}$ is characterized by at least two well-formed turns. The screw-sense of the helical structure is logically right-handed as imposed by the $S$ configuration of the sitbe side chains, resulting in negative $\varphi$ dihedral angles. Another noteworthy feature is that the achiral NtBu glycine residues at the extremities of $\mathbf{8}^{\prime}$ (positions 1, 2, 7 and 8 of the sequence) adopt the same rotational state as the chiral Nsitbe residues 3-6. In other words, the crystal structure of 8' doesn't show any screw sense inversion, the negative value of $\varphi$ imposed by the sitbe side chains (residues 3-6) is transmitted towards the achiral $N t \mathrm{Bu}$ monomers. The structure of $\mathbf{8}$ ' exhibits a remarkable conformational regularity without important jump of dihedral angles when moving along the sequence, even considering the residues at the extremities. The $\chi_{1}$ values are again close to $-100^{\circ}$, confirming the observations made for pentamer 5. In the packing, the helices pile up in a head to tail manner forming infinite stacks. (Figures $\mathrm{S}_{9}-\mathrm{S}_{3}$ )

\subsection{Analysis of peptoids oligomers 1-9, 6' and 8'}

Structural investigation was also carried out by Circular Dichroism (CD) to explore in more depth the conformation in solution and to compare with the observations made by NMR and X-Ray crystallography.

CD Analyses for homooligomers 1-9. Monomer 1 and dimer 2 displayed only weak $C D$ signals in acetonitrile with no well-defined maxima (Figure 4a). Although of weak intensity, trimer 3 exhibits a $C D$ signal that prefigures the CD signature of the longer oligomers. The CD spectra of peptoids 5, 6, 8 and 9 have a similar shape with two minima near 188 and $225 \mathrm{~nm}$ and a maximum at $209 \mathrm{~nm}$. The three maxima are red shifted by 3 to $5 \mathrm{~nm}$ going from pentamer $\mathbf{5}$ to nonamer $\mathbf{9}$. The CD spectrum of tetramer 4 also resembles those of the longer oligomers but with blue shifted maxima. Interestingly, the peramide molar ellipticity (MRE) intensities of the maximum near $209 \mathrm{~nm}$ increase with the oligomer length, with the octamer 8 and nonamer 9 displaying similar intensities. The CD spectra of $\mathbf{8}$ and $\mathbf{9}$ are indeed nearly identical in intensity and shape throughout the spectral window. The length-dependent MRE increase does suggest that helix folding of the Nstbe oligomers is a cooperative process, as previously observed for other peptoid systems containing aromatic chiral side chains (spe, sinpe, Figure 2) and chiral aliphatic side chains (sch, Figure 2). The CD spectra of the Nsitbe family were compared to the spectra obtained for peptoids containing entirely chiral aliphatic side chains. Homooligomers of $(S)-N-\left(1^{-}\right.$ cyclohexylethyl)glycine (Nsch) and (S)-N-(secbutyl)glycine (Nssb) with a free $\mathrm{N}$ terminal amino group and a carboxamide at the $\mathrm{C}$-terminus have been analysed by $C D$ at the 6-, 12- and 15-mer length. ${ }^{16}$ The CD spectra of the longer oligomers revealed a distinct $\mathrm{CD}$ signature with a maximum at $210 \mathrm{~nm}$ and two shallow minima at 200 and $225 \mathrm{~nm}$, as described by the authors. Looking carefully at the spectra in this publication, the minima 
described near $200 \mathrm{~nm}$ appear to be blue shifted around 190-195 nm. With this clarification, the CD maxima of the Nsitbe oligomers match the previously reported CD data for the Nsch and Nssb systems. We observed here that the $N$ - and $C$-termini groups have a great influence on the conformation. Indeed while the $\mathrm{H}-(\mathrm{sch})_{6}-\mathrm{CONH}_{2} \mathrm{CD}$ spectrum is weak and do not resemble those of the longer $\mathrm{Nsch}_{12}$ and $\mathrm{Nsch}_{15}$ oligomers, peptoid 7 (Ac- $(s c h)_{6^{-}}$ $\mathrm{COO} t \mathrm{Bu}$ ), exhibits $\mathrm{CD}$ spectral features that resemble those of the Nsitbe oligomers. However, by comparison of the intensities of the CD curves of the two hexamers 6 (Nsitbe) and $\mathbf{7}$ (Nsch), it is obvious that peptoid $\mathbf{7}$ displays a greater extent of backbone flexibility. The short length Nsitbe $_{3}$ (3) and Nsitbe $_{4}$ (4) oligomers present a distinct $\mathrm{CD}$ signature reminiscent of the $\mathrm{CD}$ spectra of longer Nsitbe peptoids. This suggests that a nascent ordered helical fold may appear at the trimer or tetramer length when a first helical turn has been formed. Regarding the maxima intensities, the CD spectra of (Nsttbe) $)_{n}$ more closely resemble those of $(N s s b)_{n}$ peptoids. Indeed the CD bands at $225 \mathrm{~nm}$ are reduced in intensity among Nsitbe and Nssb oligomers relative to the Nsch peptoids. Furthermore, the CD bands at $225 \mathrm{~nm}$ decrease in a lengthdependent manner among Nsitbe peptoids, which can also reflect a cooperative effect. The reduced intensity near $225 \mathrm{~nm}$ for peptoids substituted with sec-butyl side chains $(s s b)$ relative to peptoids with cyclohexylethyl side chains (sch) was interpreted as a sign of greater flexibility of Nssb peptoids. In light of CD data of the Nsitbe pep-

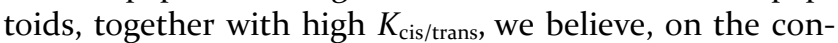
trary, that the reduced CD band at $225 \mathrm{~nm}$ is indicative of a strong conformational ordering. We also note that the $\mathrm{CD}$ shape and relative intensities of the three $\mathrm{CD}$ bands of Nsitbe peptoids, i.e. a weak negative band at $225 \mathrm{~nm}$, and

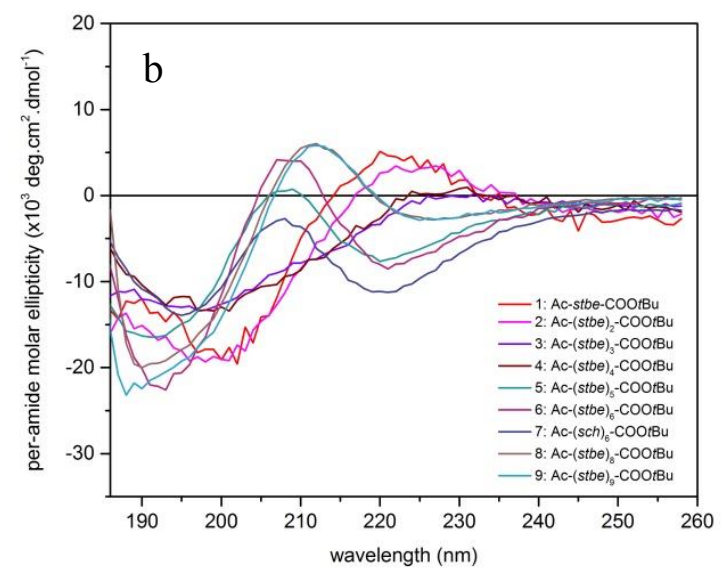

Figure 4. CD spectra of peptoids 1-9 at $\sim 500 \mu \mathrm{M}$. (a) in acetonitrile. (b) in methanol.

two intense bands, a negative near $190 \mathrm{~nm}$ and a positive near $210 \mathrm{~nm}$, are in good agreement with the CD of proline-rich polypeptides in the PPI conformation. ${ }^{21}$ We next studied sensitivity to solvent effect on changing the solvent from acetonitrile to methanol (Figure $4 \mathrm{~b}$ ). The CD shape of a PPI-type helical conformation was achieved at the pentamer stage and beyond. Indeed, the CD spectra of the longer oligomers 5, 6, 8 and 9 resemble those obtained in acetonitrile with the difference that the bands at $210 \mathrm{~nm}$ are reduced in intensities despite higher overall backbone amide $K_{\text {cis/trans }}$ in $\mathrm{MeOH}$ than in acetonitrile, as measured by NMR. The CD spectra of $\mathbf{1}$ and $\mathbf{2}$ are essentially characterized by an intense minimum around 200 $\mathrm{nm}$ and a maximum near $220 \mathrm{~nm}$. Trimer 3 and tetramer 4 exhibit a similar CD pattern, which differ from that of the longer oligomers. It is likely that they adopt a specific conformation in solution which differs from a nascently helical structure, despite the high overall ratio of backbone cis-amides, $75 \%$ for $3\left({ }^{\left(\mathrm{CD}_{3} \mathrm{OD}\right.} K_{\text {cis/trans }}=3.0\right)$ and $\sim 100 \%$ for $4\left(K_{\text {cis/trans }}>19\right)$.
CD Analyses for heterooligomers 6' and 8'. The CD spectra of heterooligomers Ac- $t B u-(s i t b e)_{4}-t B u-\mathrm{CO}_{2} t \mathrm{Bu}$ $\left(6^{\prime}\right)$ and $A c-(t B u)_{2}-(s i t b e)_{4}-(t B u)_{2}-\mathrm{CO}_{2} t \mathrm{Bu}\left(\mathbf{8}^{\prime}\right)$ were compared to their related homooligomers 6 and 8 (Figure 5). In acetonitrile a significant decrease in intensity of the minima near $188 \mathrm{~nm}$ was observed for 6' and 8' relative to 6 and 8 while the rest of the curves remained broadly unchanged. For example, the two hexamers $\mathbf{6}$ and $\mathbf{6}$ ' have both a positive maximum and a second minimum centred at $208 \mathrm{~nm}$ and $224 \mathrm{~nm}$, respectively, the per-amide molar ellipticity of 6 ' being slightly increased at $208 \mathrm{~nm}$ relative to that of 6 . This increase in ellipticity at about $210 \mathrm{~nm}$ for the heterooligomers is much more pronounced in $\mathrm{MeOH}$, which can be attributed to an increased helicity of $\mathbf{6}^{\prime}$ and $\mathbf{8}^{\prime}$ in this protic solvent. Interestingly, regardless the solvent, acetonitrile or $\mathrm{MeOH}$, no decrease of ellipticity or even an increase in $\mathrm{MeOH}$, was observed despite the presence of achiral $t \mathrm{Bu}$ side chain at the extremities of the sequences of $6^{\prime}$ and $8^{\prime}{ }^{1}{ }^{13 b}$ This means that the inner tetrameric chiral segment is able to control the overall twist 
sense of the backbone, which is in accordance with the XRay crystal structure of octamer 8'. Interestingly, in oligomers 6' and 8', a two-way communication appears to occur between the chiral core and the $t \mathrm{Bu}$ residues at the extremities. On the one hand, the $\mathrm{N} t \mathrm{Bu}$ residues help promote a higher conformational homogeneity of the inner chiral segment, on the other hand, the helical handedness of the chiral core is propagated towards the extremities giving rise for the first time to homogeneous and robust helices containing only aliphatic residues. It will be interesting to see how, in the future, the degree of peptoid helicity can vary with the amount of chiral itbe side chains and their site-specific incorporation in mixed oligomers containing $\alpha$-chiral Nsitbe and achiral $\mathrm{N} t \mathrm{Bu}$ monomers. ${ }^{22}$

Thermal stability of the Nsitbe system was also probed. For this study, spectra of nonamer 9, the longest of the series, were acquired over the temperature range $15-75^{\circ} \mathrm{C}$, increasing the temperature by $5^{\circ} \mathrm{C}$ (Figure 6). Only slight decreases of intensities were observed as the temperature increased, confirming the exceptional stability of oligopeptoids adopting the all-cis PPI-type helical conformation. The $\mathrm{CD}$ spectrum after cooling down to $15^{\circ} \mathrm{C}$ was also shown to be perfectly superposable to the initial spectrum acquired at this temperature. Finally, from compound 9, it was also verified that the CD spectral shape and intensity were not dependent on the concentration (Figure S14)
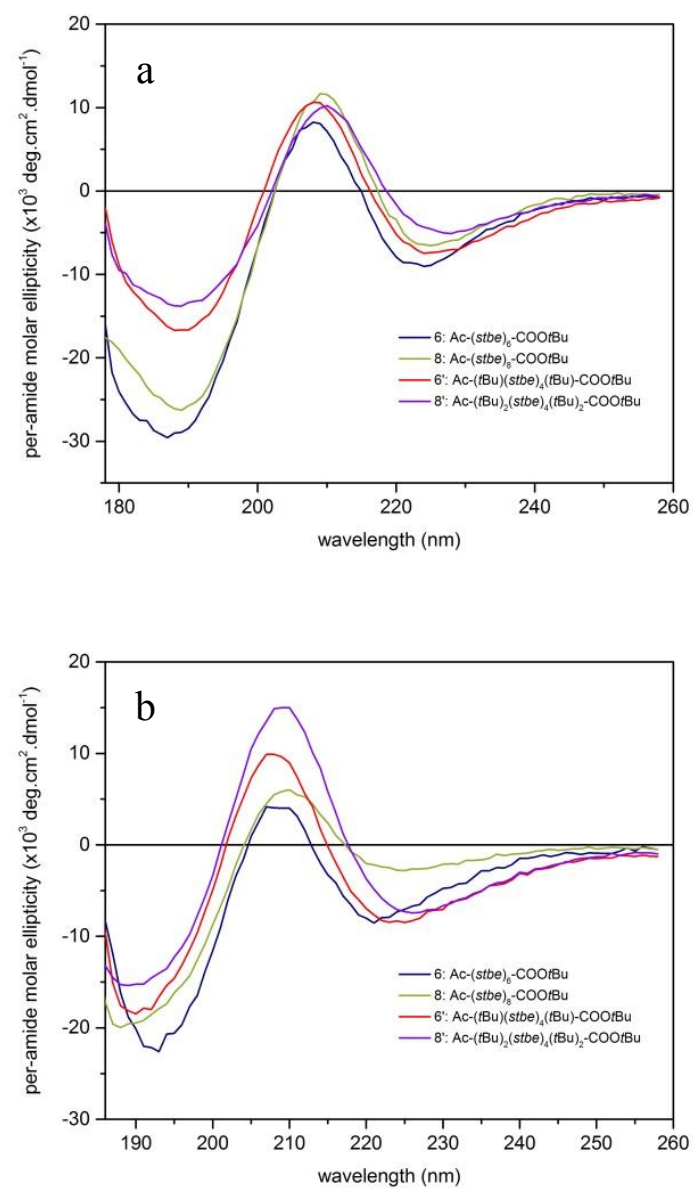

Figure 5. CD spectra of peptoids 6, 8, 6' and $\mathbf{8}^{\prime}$ at $\sim 500$ $\mu \mathrm{M}$. a) in acetonitrile. b) in methanol

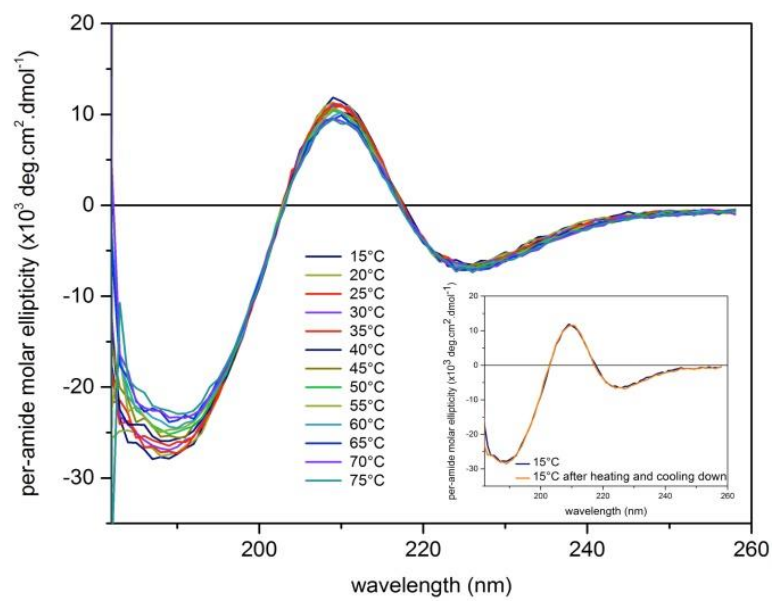

Figure 6. CD spectra of peptoid 9 at $\sim 500 \mu \mathrm{M}$ in acetonitrile. Data were collected between $15-75^{\circ} \mathrm{C}$ in $5^{\circ}$ increments. On inset, CD spectra collected at $15^{\circ} \mathrm{C}$ before and after the temperature ramp.

\section{Summary and outlook}

The discrete and predictable folding of peptoids largely depends on the capacity of the attached side chains to individually establish local interactions with the backbone, notably to control the cis/trans equilibria of pep- 
toid amides. Chirality which can be introduced through the side chains is also critical to get well-folded secondary structures of defined handedness. This goal was achieved in the past with side chains comprising an aromatic moiety. Hence, homooligomers bearing chiral $(S)$ 1- $^{-}$ naphthylethyl side chain form well-folded PPI helices with all-cis amides. Our objective was to construct for the first time conformationally homogeneous peptoid PPI helices composed exclusively of $N$-alkyl glycine monomers and of defined handedness. Based on the fact that side chain steric hindrance is one of the best means for ensuring conformational restriction of peptoid chains and promote their folding in all-cis PPI helices, we have identified a new aliphatic chiral side chain favouring the cis conformation. We have discovered that (S)-N-(1-tertbutylethyl)glycine homooligomers are capable of forming conformationally homogeneous and stable PPI helices. This is supported first by high overall amide $K_{\text {cis/trans, }}$, particularly in chloroform and methanol solvents in which all-cis structures are observed from the tetramer length. The X-ray crystal structure of pentamer 5 revealed a righthanded helix featuring backbone dihedral angles consistent with those of PPI peptide and peptoid helices. Homopeptoids 1-9 feature length-dependent CD curves suggesting a folding cooperative process as already observed for peptoids with $\alpha$-chiral aromatic side chains. The CD signature is reminiscent that of PPI peptide helices, in contrast with that of peptoids with $\alpha$-chiral aromatic side chains. The longest solid state structure for any linear peptoid was obtained for octamer 8' (Ac$\left.(t \mathrm{Bu})_{2}(s i t b e)_{4}(t \mathrm{Bu})_{2}-\mathrm{COO} t \mathrm{Bu}\right)$. Despite the reduced number of chiral side chains $(50 \%)$, octamer $\mathbf{8}^{\prime}$ forms a very regular right-handed PPI helical structure in the solid state. The all-cis arrangement characterizing PPI helices was also verified in solution $\left(\mathrm{CDCl}_{3}\right.$ and $\left.\mathrm{CD}_{3} \mathrm{CN}\right)$ for $\mathbf{8}^{\prime}$ and also for hexamer 6' (Ac- $\left.(t \mathrm{Bu})(s i t b e)_{4}(t \mathrm{Bu})-\mathrm{COO} t \mathrm{Bu}\right)$. All together these results suggest that the $\mathrm{N} t \mathrm{Bu}$ residues strengthen the conformational stability of the inner chiral segment, on the other hand, the helical handedness of the chiral core is propagated towards the extremities giving rise for the first time to homogeneous and robust helices comprising only aliphatic residues. Site sequence specific incorporation of achiral tert-butyl side chains in Nsitbe oligomers will be studied to delineate boundaries of this new system.

This work opens up excellent prospects for new peptoid design based foldamers with chemical and biological applications, including asymmetric catalysis, ${ }^{2 a}$ selective recognition of metal ions ${ }^{4 a}$ and targeting helix-mediated protein-protein interactions. ${ }^{23}$ Helices contribute more than $60 \%$ to protein-protein interfaces ${ }^{24}$ and modulators of protein-protein interactions are now considered promising candidates in drug development. Peptoid helices have undeniably a major role to play in this regard. Their conformation is not stabilized by intramolecular hydro- gen bonds; and consequently is less likely to be influenced by the environment. The itbe side chains could participate to hydrophobic contacts which are crucial in a number of protein-protein interactions. The future design of inhibitors of protein-protein interactions based on the ttbe side chain will need to introduce solubilizing groups, for example at non interacting positions, to improve their aqueous solubility.

\section{ASSOCIATED CONTENT}

Supporting Information. Experimental procedures for peptoid synthesis, characterization data for peptoid monomer 1. HPLC and MS data for peptoids 1-9, 6' and 8'. ' ${ }^{1} \mathrm{H}$ and COSY spectra for peptoid oligomers. X-ray crystallographic data for peptoids $\mathbf{5}$ and $\mathbf{8}$ ' and CD data for peptoid oligomers. This material is available free of charge via the Internet at http://pubs.acs.org

\section{AUTHOR INFORMATION}

\section{Corresponding Author}

olivier.roy@uca.fr

claude.taillefumier@uca.fr.

\section{Author Contributions}

The manuscript was written through contributions of all authors. / All authors have given approval to the final version of the manuscript. / \$These authors contributed equally. (match statement to author names with a symbol)

\section{Funding Sources}

This work was supported by the ANR ARCHIPEP project, grant ANR Blanc - SIMI 72013 of the French Agence Nationale de la Recherche.

\section{ACKNOWLEDGMENT}

We would like to acknowledge Aurélie Job (HPLC) and Martin Leremboure (mass spectrometry) for their assistance. Circular dichroism experiments were performed thanks to the SCBIM (Service Commun de Biophysique Interactions Moléculaires, Fédération de Recherche 3209 BMCT) of Université de Lorraine.

CCDC 1561294-1561295 contains the supplementary crystallographic data for this paper. The data can be obtained free of charge from The Cambridge Crystallographic Data Centre via www.ccdc.cam.ac.uk/structures.

\section{REFERENCES}


(1) (a) Simon, R. J.; Kania, R. S.; Zuckermann, R. N.; Huebner, V. D.; Jewell, D. A.; Banville, S.; Ng, S.; Wang, L.; Rosenberg, S.; Marlowe, C. K.; Tan, R.; Frankel, A. D.; Santi, D. V.; Cohen, F. E.; Bartlett, P. A. Proc. Natl. Acad. Sci. USA 1992, 89, 9367-9371. (b) Patch, J. A.; Kirshenbaum, K.; Seurynck, S. L.; Zuckermann, R. N.; Barron, A. E. Versatile Oligo(N-Substituted) Glycines: The Many Roles of Peptoids. In Drug Discovery; Wiley-VCH Weinheim, Germany: 2004; pp 1-31. (c) Zuckermann, R. N.; Kodadek, T. Curr. Opin. Mol. Ther. 20o9, 11, 299-307. (d) Dohm, M. T.; Kapoor, R.; Barron, A. E. Curr. Pharm. Des. 2011, 17, 2732-2747. (e) Lau, K. H. A. Biomat. Sci. 2014, 2, 627-633. (f) Knight, A. S.; Zhou, E. Y.; Francis, M. B.; Zuckermann, R. N. Adv. Mater. 2015, 27, 5665.

(2) (a) Maayan, G.; Ward, M. D.; Kirshenbaum, K. Proc. Natl. Acad. Sci.USA 20o9, 106, 13679-13684. (b) Prathap, K. J.; Maayan, G. Chem. Commun. 2015, 51, 11096-11099. (c) Schettini, R.; De Riccardis, F.; Della Sala, G.; Izzo, I. J. Org. Chem. 2016, 81, $2494-2505$.

(3)Fuller, A. A.; Yurash, B. A.; Schaumann, E. N.; Seidl, F. J. Org. Lett. 2013, 15, 5118-5121

(4) (a) Baskin, M.; Maayan, G. Chem. Sci. 2o16, 7, 2809-282o. (b) Lee, B. C.; Chu, T. K.; Dill, K. A.; Zuckermann, R. N. J. Am. Chem. Soc. 2008, 130, 8847-8855. (c) Sala, G. D.; Nardone, B.; De Riccardis, F.; Izzo, I. Org. Biomol Chem. 2o13, 11, 726-731. (d) De Cola, C.; Licen, S.; Comegna, D.; Cafaro, E.; Bifulco, G.; Izzo, I.; Tecilla, P.; De Riccardis, F. Org. Biomol. Chem. 2009, 7, 2851-2854. (e) Maayan, G.; Ward, M. D.; Kirshenbaum, K. Chem. Commun. 2009, 56-58. (f) De Cola, C.; Fiorillo, G.; Meli, A.; Aime, S.; Gianolio, E.; Izzo, I.; De Riccardis, F. Org. Biomol. Chem. 2014, 12, 424-431. (g) Knight, A. S.; Zhou, E. Y.; Pelton, J. G.; Francis, M. B. J. Am. Chem. Soc. 2013, 135, 17488-17493. (h) Baskin, M.; Maayan, G. Biopolymers 2015, 104, 577-584. (i) De Santis, E.; Edwards, A. A.; Alexander, B. D.; Holder, S. J.; Biesse-Martin, A. S.; Nielsen, B. V.; Mistry, D.; Waters, L.; Siligardi, G.; Hussain, R.; Faure, S.; Taillefumier, C. Org. Biomol. Chem. 2016, 14, 11371-11380

(5) (a) Sui, Q.; Borchardt, D.; Rabenstein, D. L. J. Am. Chem. Soc. 2007, 129, 12042-12048. (b) Butterfoss, G. L.; Renfrew, P. D.; Kuhlman, B.; Kirshenbaum, K.; Bonneau, R. J. Am. Chem. Soc. 2009, 131, 16798-16807. (c) Voelz, V. A.; Dill, K. A.; Chorny, I. Biopolymers 2011, 96, 639-650. (d) Engel-Andreasen, J.; Wich, K.; Laursen, J. S.; Harris, P.; Olsen, C. A. J. Org. Chem. 2015, 80, 5415-5427.

(6) Shah, N. H.; Butterfoss, G. L.; Nguyen, K.; Yoo, B.; Bonneau, R.; Rabenstein, D. L.; Kirshenbaum, K. J. Am. Chem. Soc. 2oo8, 13o, 16622-16632.

(7) Armand, P.; Kirshenbaum, K.; Falicov, A.; Dunbrack Jr, R. L.; Dill, K. A.; Zuckermann, R. N.; Cohen, F. E. Fold. Des. 1997, 2 , 369375 .

(8) Gopalakrishnan, R.; Frolov, A. I.; Knerr, L.; Drury III, W. J.; Valeur, E. J. Med. Chem. 2016, 59, 9599-9621.

(9) Armand, P.; Kirshenbaum, K.; Goldsmith, R. A.; Farr-Jones, S.; Barron, A. E.; Truong, K. T. V.; Dill, K. A.; Mierke, D. F.; Cohen, F. E.; Zuckermann, R. N.; Bradley, E. K. Proc. Natl. Acad. Sci. USA, 1998, 95, 4309-4314.

(10) Gorske, B. C.; Stringer, J. R.; Bastian, B. L.; Fowler, S. A.; Blackwell, H. E. J. Am. Chem. Soc. 2009, 131, 16555-16567.

(11) (a) Stringer, J. R.; Crapster, J. A.; Guzei, I. A.; Blackwell, H. E. J. Am. Chem. Soc. 2011, 133, 15559-15567. (b) (b) Laursen, J. S.; Harris, P.; Fristrup, P.; Olsen, C. A. Nat. Commun. 2015, 6, 7013.

(12) (a) Caumes, C.; Roy, O.; Faure, S.; Taillefumier, C. J. Am. Chem. Soc. 2012, 134, 9553-9556. (b) Aliouat, H.; Caumes, C.; Roy, O.; Zouikri, M.; Taillefumier, C.; Faure, S. J. Org. Chem. 2017, 82, 2386-2398.

(13) (a) Roy, O.; Caumes, C.; Esvan, Y.; Didierjean, C.; Faure, S.; Taillefumier, C. Org. Lett. 2013, 15, 2246-2249. (b) Angelici, G.; Bhattacharjee, N.; Roy, O.; Faure, S.; Didierjean, C.; Jouffret, L.; Jolibois, F.; Perrin, L.; Taillefumier, C. Chem. Commun. 2o16, 52, 4573-4576.

(14) Culf, A. S.; Ouellette, R. J. Molecules 2010, 15, 5282-5335.

(15) Mixtures of truncated (NtBu) oligomers observed by LCMS.

(16) Wu, C. W.; Kirshenbaum, K.; Sanborn, T. J.; Patch, J. A.; Huang, K.; Dill, K. A.; Zuckermann, R. N.; Barron, A. E. J. Am. Chem. Soc. 2003, 125, 13525-13530.

(17) Gorske, B. C.; Blackwell, H. E. J. Am. Chem. Soc. 20o6, 128, 14378-14387.

(18) (a) Shin, S. B.; Yoo, B.; Todaro, L. J.; Kirshenbaum, K. Cyclic Peptoids. J. Am. Chem. Soc. 20o7, 129, 3218-3225. (b) Caumes, C.; Fernandes, C.; Roy, O.; Hjelmgaard, T.; Wenger, E.; Didierjean, C.; Taillefumier, C.; Faure, S. Org. Lett. 2013, 15, 3626-3629. (c) Culf, A. S.; Cuperlovic-Culf, M.; Léger, D. A.; Decken, A. Org. Lett. 2014, 16, 2780-2783

(19) (a) Gorske, B. C.; Nelson, R. C.; Bowden, Z. S.; Kufe, T. A.; Childs, A. M. J. Org. Chem. 2013, 78, 11172-11183

(20) Schreiner, P. R.; Chernish, L. V.; Gunchenko, P. A.; Tikhonchuk, E. Y.; Hausmann, H.; Serafin, M.; Schlecht, S.; Dahl, J. E. P.; Carlson, R. M. K.; Fokin, A. A. Nature, 2011, 477, 308-312.

(21) (a) Rabanal, F.; Ludevid, M. D.; Pons, M. ; Giralt, E. Biopolymers 1993, 33, 1019-1028. (b) Mutter, M.; Wöhr, T.; Gioria, S.; Keller, M. Biopolymers 1999, 51, 121-128.

(22) Shin, H. M.; Kang, C. M.; Yoon, M. H.; Seo, J. Chem. Commun. 2014, 50, 4465-4468.

(23) Pelay-Gimeno, M.; Glas, A.; Koch, O.; Grossmann, T. N. Angew. Chem. Int. Ed. 2015, 54, 8896-8927.

(24) Bullock, B. N., Jochim, A.L., Arora, P.S. J. Am. Chem. Soc. 2011, 133, 14220-14223.

\section{Insert Table of Contents artwork here}




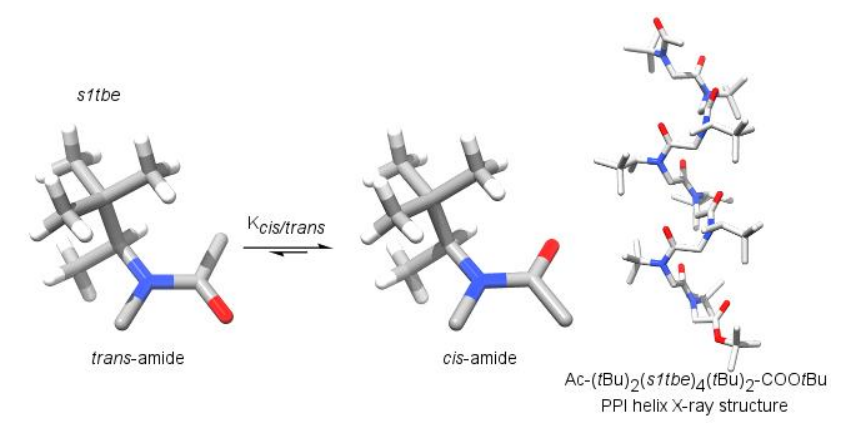

